УДК 330.567 .25

ББК 65.26

DOI 10.31554/2222-9175-2021-44-121-129

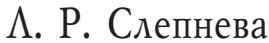

СБЕРЕГАТЕАЬНЫЙ ПОТЕНЦИАА АОМОХОЗЯЙСТВ

В УС ОВИЯХ ФИНАНСОВО-ЭКОНОМИЧЕСКОЙ НЕСТАБИАЬНОСТИ (на примере регионов АФО)

Статья посвящена исследованию сберегательного поведения и оценке сберегательного потенциала домохозяйств в условиях финансово-экономической нестабильности. Показано, что величина инвестируемых в экономику сбережений непосредственно зависит от стабильности финансово-экономической ситуации. Дано авторское видение структурно-сущностных аспектов понятия «сберегательный потенциал» домохозяйств. На примере регионов ДФО проанализирован сберегательный потенциал домохозяйств.

Ключевые слова: сбережения, отложенное потребление, доходы населения, сберегательный потенциал, сберегательное поведение, финансово-экономическая нестабильность, мотивы сбережений домохозяйств.

L. R. Slepnyova

\title{
SAVINGS POTENTIAL OF HOUSEHOLDS IN THE CONDITIONS OF FINANCIAL AND ECONOMIC INSTABILITY (using the example of the regions of the Far Eastern Federal District)
}

The article focuses on the study of savings behaviour and the assessment of the savings potential of households in conditions of financial and economic instability. It had been shown that the amount of savings invested in the economy depended directly on the stability of the financial and economic situation. The author's vision of the structural and essential aspects of the concept of «savings potential» of households is given. On the example of regions of the FEFD the savings potential of households is analyzed.

Keywords: savings, the postponed consumption, the income of the population, savings potential, savings behavior, financial and economic instability, motives of savings of households.

\section{Обоснование проблемы исследования}

Пеструктивные последствия вводимых из-за пандемии ограничений, высокая волатильность национальной валюты, падение реальных располагаемых доходов и изменения структуры расходов домохозяйств (ввиду объективных и субъективных факторов) во многом способствовали трансформации сберегательного поведения и сберегательного потенциала населения. В структуре ВВП расходы на конечное потребление (в постоянных ценах), в т. ч. домашних хозяйств, снизились в 2020 г. в сравнении с 2019 г. соответственно на 3524,2 млрд руб. (или на 5,5\%) и 4344,5 млрд руб. (или на 8,7 \%) при уменьшении валового накопления с 21379,9 млрд руб. в 2019 г. до 20958,0 млрд руб. в 2020 г. (или на 2,0 \%) [Доходы, расходы и потребление...]. Следует отметить, что при сокращении объема реальных доходов населения России в 2020 г. в сравнении с 2019 г. на 3,0 \% вследствие уменьшения доходов от предпринимательской деятельности и собственности, сбережения существенно возросли [Доходы россиян снизились...]. Межрегиональные сопоставления по величине сберегательного потенциала свидетельствуют о неравномерности его распределения. Данное обстоятельство актуализирует исследование причин и спе-

СЛЕПНЕВА Людмила Романовна - доктор экономических наук, профессор, декан факультета экономики и управления Федерального государственного бюджетного образовательного учреждения высшего образования Восточно-Сибирский государственный университет технологий и управления (г. Улан-Удэ, Россия). E-mail: slluro@ mail.ru. 
цифических характеристик сберегательного поведения в условиях финансово-экономической нестабильности, анализа сберегательного потенциала домохозяйств в регионах России. Особенно актуально данное исследование для регионов, входящих в ДФО, существенно разнящихся по норме и объему сбережений как фактора роста инвестирования в экономику региона.

\section{Основные концепты и степень изученности проблемы}

В общепринятом понимании сбережения домохозяйств представляют собой аккумулируемую, неизрасходованную часть дохода или «отложенное потребление»; являются экономически эффективными и целесообразными при условии, если отложенная сумма приносит доход, а величина приведенного дохода превышает выгоду от текущего расходования. Изменяющиеся пропорции между объемом сбережений и величиной потребления определяют сберегательные возможности (сберегательный потенциал) и зависят, в числе многих факторов, от модели (стратегии) сберегательного поведения домохозяйств, трансформируемой под влиянием таких факторов и условий, как финансово-экономические, социокультурные, политико-правовые, демографические, психологические, институциональные и др.

Для полноты и объективности оценки сберегательного потенциала, а также исследования специфических характеристик сберегательного поведения разных групп домохозяйств отечественными и зарубежными учеными предложены разные подходы к систематизации перечисленных выше и других факторов. Так, факторы, оказывающие влияние на сберегательное поведение и объем сбережений в условиях кризиса, подразделяют на группы, определяющие цели, временной период, функциональное назначение, экономические потребности и непосредственно процесс сбережения [Каврук 2010]. При этом под влиянием осознанных и неосознанных мотивов формируются мотивированные (для удовлетворения потребностей второго порядка и будущих периодов, на обеспечение финансовой самостоятельности и поддержание социального статуса) и вынужденные (вследствие высокого темпа роста доходов, из-за несоответствия рыночного спроса и предложения по отдельным группам товаров, для инвестирования в доходные активы) сбережения.

Основываясь на положениях системного подхода, факторы и условия подразделяют на внутренние, зависящие от внутреннего потенциала домохозяйств (доходно-имущественные, предпринимательские, потребительские, психологические, культурно-образовательные и определяющие социальный статус) и внешние, почти или полностью не зависящие от потенциала членов домохозяйств (социально-политические и правовые, финансово-экономические и институциональные, демографические и трудовые, экологические и природно-ресурсные) [Маратканова 2019]. Учитывая разную степень влияния перечисленных факторов, предложено моделировать сберегательное поведение и стимулировать привлечение сбережений в инвестиционные структуры.

С позиции институционального подхода основное влияние на сберегательное поведение оказывает институциональная среда государства; не вся непотраченная часть дохода может рассматриваться в качестве сбережений [Елисеев и др. 2013]. Последнее обусловлено тем, что низкие доходы способствуют почти полному трансформированию финансовых ресурсов в текущее потребление, небольшие «остатки» образуют отложенный спрос, расходуемый в будущем (чаще в краткосрочном периоде).

Аккумулированный с целью накопления доход может принимать форму инвестиционных ресурсов и сбережений [Семенюта, Гончаренко 2011]. При этом формирование сберегательного потенциала связано с накоплением и использованием финансовых ресурсов домохозяйств, которые они склонны при определенных условиях инвестировать в экономику.

Приведенные выше выводы и научные результаты ученых свидетельствуют о важности учета факторов и условий, способных стимулировать либо тормозить сбережения домохозяйств. На современном этапе условия финансово-экономической нестабильности и склонность к формированию «отложенных на будущее» резервов 
являются важнейшими факторами, влияющими на уровень сбережений, оказывают отрицательное влияние на сберегательное поведение домохозяйств и в совокупности с другими воздействуют на сберегательный потенциал.

Аккумулируемая в виде сбережений часть дохода включает: текущий резерв, создаваемый для поддержания привычного уровня потребления, в т. ч. в случае сокращения по разным причинам объема располагаемого дохода; страховой резерв, формируемый для обеспечения будущих капитальных расходов, в т. ч. для приобретения дорогостоящих товаров длительного пользования; сберегательный резерв (инвестиционное накопление), предназначенный для инвестирования в доходные активы и получения дополнительного дохода в будущем. Именно накопленные резервы обеспечивают «подушку» финансовой безопасности и покрывают отложенный спрос.

По мнению автора, под сберегательным потенциалом следует понимать максимально возможный объем аккумулируемых ресурсов, который при определенных условиях домохозяйства склонны инвестировать в экономику региона, страны. Важнейшим критерием таких благоприятных для инвестирования условий является финансово-экономическая стабильность. В структуре сберегательного потенциала следует выделять три части: потребительскую, инвестиционно-предпринимательскую и накопительную (рис. 1).

Резюмируя вышеизложенное, можно сделать следующие выводы. Во-первых, на сберегательное поведение и величину сберегательного потенциала оказывает влияние ряд факторов, важнейшими из которых на современном этапе являются условия финансово-экономической нестабильности и склонность к формированию сбережений. Во-вторых, сберегательный потенциал домохозяйств как максимально возможный объем сбережений лишь частично инвестируется в экономику, при этом величина инвестируемых сбережений непосредственно зависит от стабильности финансово-экономической ситуации. В-третьих, величина сбережений домохозяйств имеет номинальную и реальную оценку; при этом чем на более длительный срок отложено потребление, тем выше разрыв между номинальной и реальной стоимостью. В-четвертых, разница между номинальной и реальной стоимостью в оценке сберегательного потенциала обусловлена «сберегательной инфляцией». В-пятых, сбережения домохозяйств, накапливаемые неорганизованно, характеризуются

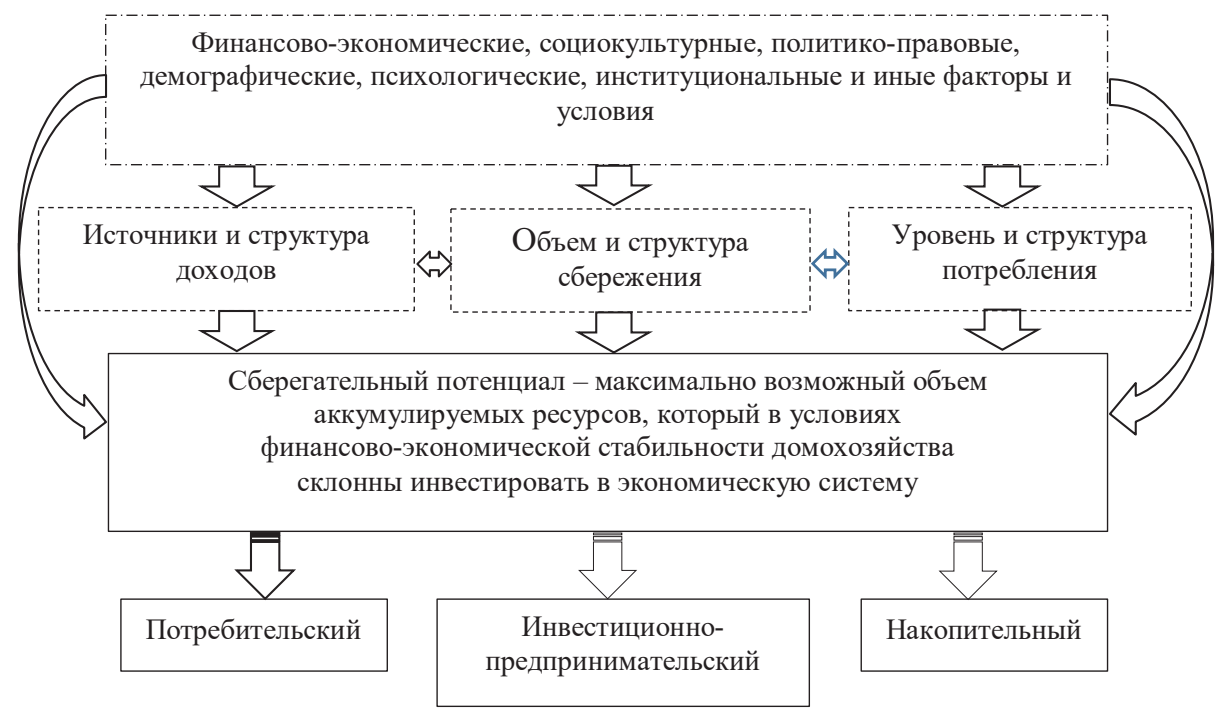

Рис. 1. Структурно-сущностные аспекты понятия «сберегательный потенциал» домохозяйств 
более высокой ликвидностью, однако сильнее подвержены влиянию «сберегательной инфляции».

\section{Результаты исследования и их интерпретация}

В динамике трехлетнего периода в регионах ДФО отмечается рост среднедушевых денежных доходов населения (за исключением Республики Саха (Якутия), где в 2020 г., по сравнению с 2019 г., наблюдается несущественное снижение). Самый большой прирост в 2020 г., по сравнению с 2018 г., отмечен в Магаданской области $(14,3 \%)$, Чукотском автономном округе $(13,5 \%)$ и Сахалинской области $(11,8 \%)$; самый низкий - в Республике Бурятия (7,0 \%) и Хабаровском крае (6,8 \%) (рис. 2).

Повышение среднедушевых денежных доходов способствовало изменению структуры их расходования. Так, в среднем в регионах ДФО доля расходов на покупку товаров и оплату услуг снизилась с 81,0 \% в 2018 г. до 76,1 \% в 2020 г. при увеличении расходов на уплату взносов и обязательных платежей с 15,0 \% в 2018 г. до 15,4 \% в 2020 г. Доля сбережений населения увеличилась за анализируемый период на 2,5 процентных пункта (с 1,7 \% в 2018 г. до 4,2 \% в 2020 г.), доля наличных средств (в национальной и иностранной валюте в рублевом эквиваленте) - на 1,8 процентных пункта (с 2,5 \% в 2018 г. до 4,3 \% в 2020 г.). То есть рост среднедушевых денежных доходов способствовал увеличению сбережений, при этом темп прироста сбережений опережает темп прироста наличных средств на руках у населения.

Объем располагаемых ресурсов домохозяйств из сельской местности, как правило, ниже располагаемых ресурсов городских домохозяйств (табл.1). Самое большое расхождение в объеме располагаемых ресурсов городских и сельских жителей в среднем на члена домашнего хозяйства отмечено в 2020 г. в Чукотском автономном округе, Республике Саха (Якутия) и Магаданской области (примерно в 1,6 раза); самое низкое - в Еврейской автономной области (около 1,2 раза).

В динамике рассматриваемого периода произошло снижение располагаемых ресурсов домохозяйств, находящихся на сельских территориях, в Республике Саха (Якутия), Амурской области, Еврейской автономной области. В отдельных регионах отмечено снижение располагаемых ресурсов домохозяйств как в сельской,

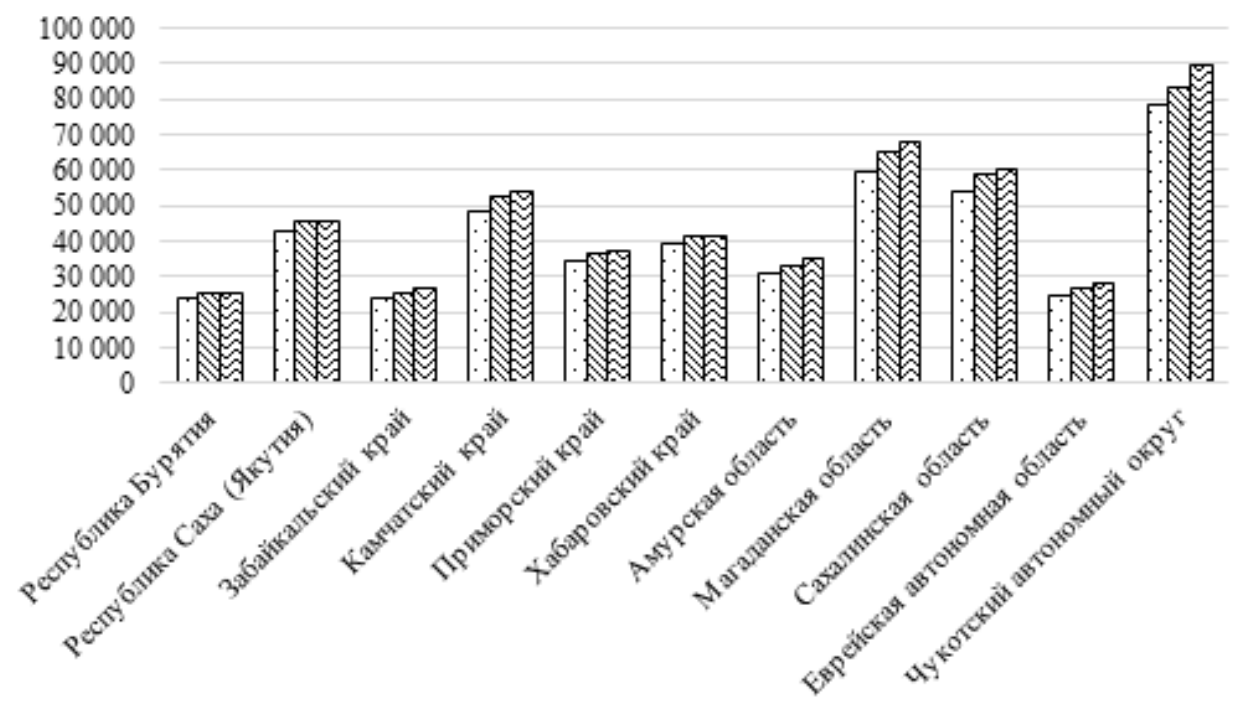

口2018r. \2019r. च2020r.

Рис. 2. Среднедушевые денежные доходы населения в регионах ДФО, руб. в месяц. Сост. по: [Уровень жизни] 
так и городской местности (Камчатский и Приморский края). В большей степени это обусловлено сужением рынка труда и проявлением последствий карантинных ограничений из-за продолжения пандемии.

Таблица 1

Располагаемые ресурсы домохозяйств в зависимости от места расположения, в среднем на члена домашнего хозяйства в месяц, тыс. руб.

\begin{tabular}{|c|c|c|c|c|c|c|c|c|c|}
\hline \multirow{3}{*}{ Регион } & \multicolumn{3}{|c|}{2018 г. } & \multicolumn{3}{|c|}{2019 г. } & \multicolumn{3}{|c|}{2020 г. } \\
\hline & \multirow{2}{*}{$\begin{array}{c}\text { Все } \\
\text { домохо- } \\
\text { зяйства }\end{array}$} & \multicolumn{2}{|c|}{$\begin{array}{c}\text { прожива- } \\
\text { ющие в } \\
\text { местности } \\
\end{array}$} & \multirow{2}{*}{$\begin{array}{c}\text { Все } \\
\text { домохо- } \\
\text { зяйства }\end{array}$} & \multicolumn{2}{|c|}{$\begin{array}{l}\text { прожива- } \\
\text { ющие в } \\
\text { местности }\end{array}$} & \multirow{2}{*}{$\begin{array}{c}\text { Bсе } \\
\text { домохо- } \\
\text { зяйства }\end{array}$} & \multicolumn{2}{|c|}{$\begin{array}{l}\text { прожива- } \\
\text { ющие в } \\
\text { местности }\end{array}$} \\
\hline & & $\begin{array}{l}\text { город- } \\
\text { ской }\end{array}$ & $\begin{array}{l}\text { сель- } \\
\text { ской }\end{array}$ & & $\begin{array}{l}\text { город- } \\
\text { ской }\end{array}$ & $\begin{array}{l}\text { сель- } \\
\text { ской }\end{array}$ & & $\begin{array}{l}\text { город- } \\
\text { ской }\end{array}$ & $\begin{array}{l}\text { сель- } \\
\text { ской }\end{array}$ \\
\hline $\begin{array}{l}\text { Республика } \\
\text { Бурятия }\end{array}$ & 18,018 & 21,083 & 13,604 & 19,943 & 22,947 & 15,608 & 20,763 & 23,970 & 16,105 \\
\hline $\begin{array}{l}\text { Республика } \\
\text { Саха } \\
\text { (Якутия) }\end{array}$ & 40,735 & 42,405 & 37,545 & 41,840 & 44,270 & 37,140 & 43,720 & 50,122 & 31,337 \\
\hline $\begin{array}{l}\text { Забайкаль- } \\
\text { ский край }\end{array}$ & 22,780 & 25,810 & 16,276 & 26,488 & 31,008 & 16,693 & 27,125 & 31,185 & 18,426 \\
\hline $\begin{array}{l}\text { Камчатский } \\
\text { край }\end{array}$ & 42,174 & 44,422 & 34,103 & 49,323 & 52,749 & 36,882 & 48,017 & 51,489 & 35,366 \\
\hline $\begin{array}{l}\text { Приморский } \\
\text { край }\end{array}$ & 32,030 & 34,324 & 24,256 & 31,767 & 32,706 & 28,552 & 30,959 & 31,826 & 27,995 \\
\hline $\begin{array}{l}\text { Хабаровский } \\
\text { край }\end{array}$ & 33,534 & 36,161 & 21,514 & 33,903 & 36,427 & 22,371 & 37,081 & 40,086 & 23,308 \\
\hline $\begin{array}{l}\text { Амурская } \\
\text { область }\end{array}$ & 25,627 & 25,070 & 26,777 & 27,498 & 27,005 & 28,524 & 35,186 & 38,754 & 27,697 \\
\hline $\begin{array}{l}\text { Магаданская } \\
\text { область }\end{array}$ & 38,432 & 39,019 & 24,733 & 46,403 & 47,258 & 25,461 & 50,495 & 51,241 & 32,248 \\
\hline $\begin{array}{l}\text { Сахалинская } \\
\text { область }\end{array}$ & 53,651 & 58,091 & 33,395 & 40,521 & 42,047 & 33,471 & 42,221 & 43,429 & 36,586 \\
\hline $\begin{array}{l}\text { Еврейская } \\
\text { автономная } \\
\text { область } \\
\end{array}$ & 25,900 & 27,099 & 23,260 & 27,548 & 28,184 & 26,142 & 28,128 & 29,573 & 24,964 \\
\hline $\begin{array}{l}\text { Чукотский } \\
\text { автономный } \\
\text { округ }\end{array}$ & 36,211 & 39,431 & 28,685 & 40,803 & 43,395 & 34,497 & 50,417 & 56,425 & 35,317 \\
\hline
\end{tabular}

Сост. по: [Уровень жизни].

С введением «пандемийных ограничений» в 2020 г. по регионам ДФО отмечено снижение реальных доходов населения (за исключением Чукотского автономного округа, где, напротив, зафиксирован рост во II и III кварталах, табл. 2). К концу 2020 г. в большинстве регионов ситуация улучшилась и темп падения реальных доходов населения замедлился. В целом за 2020 г. рост реальных доходов населения зафиксирован в Чукотском автономном округе и Магаданской области; сохранение на прежнем уровне - в Камчатском крае. Для остальных регионов характерно снижение реальных доходов населения по итогу 2020 г. в сравнении с прошлым годом. В большей степени приведенная динамика обусловлена мерами государственной социальной поддержки, а также комплексом и продолжительностью вводимых региональными органами власти ограничительных мер. 
Таблица 2

Динамика изменения реальных денежных доходов населения в регионах ДФО в 2020 г., \% к соответствующему периоду

\begin{tabular}{|c|c|c|c|c|c|}
\hline \multirow{2}{*}{ Регион } & \multicolumn{4}{|c|}{2020 г., квартал } & \multirow{2}{*}{$\begin{array}{l}\text { Итого } \\
\text { за год }\end{array}$} \\
\hline & I & II & III & IV & \\
\hline Республика Бурятия & 100,2 & 101,6 & 91,5 & 97,7 & 97,6 \\
\hline Республика Саха (Якутия) & 103,9 & 92,7 & 96,9 & 98,6 & 97,8 \\
\hline Забайкальский край & 99,0 & 98,4 & 98,8 & 97,5 & 98,4 \\
\hline Камчатский край & 109,1 & 99,4 & 95,8 & 97,8 & 100,0 \\
\hline Приморский край & 104,3 & 96,4 & 93,4 & 95,0 & 97,0 \\
\hline Хабаровский край & 99,6 & 95,2 & 95,5 & 94,9 & 96,2 \\
\hline Амурская область & 102,7 & 97,7 & 95,9 & 99,8 & 99,0 \\
\hline Магаданская область & 102,8 & 97,9 & 98,8 & 102,4 & 100,5 \\
\hline Сахалинская область & 102,6 & 95,1 & 98,5 & 94,8 & 97,5 \\
\hline Еврейская автономная область & 100,0 & 96,5 & 99,5 & 99,5 & 98,9 \\
\hline Чукотский автономный округ & 103,1 & 104,4 & 104,8 & 107,9 & 105,1 \\
\hline
\end{tabular}

Сост. по: [Уровень жизни].

В 2020 г., по сравнению с 2019 г., в регионах ДФО изменилась структура реальных денежных доходов по источникам их формирования: в среднем доля доходов от предпринимательской деятельности и от собственности снизилась на 0,8 процентных пункта при увеличении доли заработной платы и социальных выплат на 1,5 и 2,1 процентных пункта соответственно. Основная причина сложившейся ситуации заключается в снижении из-за карантинных ограничений выручки и прибыли организаций, что способствовало уменьшению либо отмене выплат годовых премий и дивидендов, разовых вознаграждений и бонусов, иных нерегулярных сумм сотрудникам.

Благодаря беспрецедентному пакету антикризисных мер, реализуемому правительством страны в период «пандемийных ограничений», в регионах ДФО удалось несколько снизить долю населения с денежными доходами ниже величины прожиточного минимума (табл. 3). Однако относительно высокий уровень населения с денежными доходами ниже величины прожиточного минимума (практически каждый пятый) сохраняется в Республике Бурятия, Забайкальском крае и Еврейской автономной области.

Таблица 3

Динамика доли населения с денежными доходами ниже величины прожиточного минимума, \% от общей численности населения

\begin{tabular}{|l|c|c|c|}
\hline \multicolumn{1}{|c|}{ Регион } & 2018 г. & 2019 г. & 2020 г. \\
\hline \multicolumn{1}{|c|}{1} & 2 & 3 & 4 \\
\hline Республика Бурятия & 19,1 & 20,1 & 20,0 \\
\hline Республика Саха (Якутия) & 18,6 & 17,8 & 17,4 \\
\hline Забайкальский край & 21,4 & 21,5 & 21,0 \\
\hline Камчатский край & 15,8 & 14,9 & 14,9 \\
\hline Приморский край & 13,9 & 13,5 & 13,0 \\
\hline Хабаровский край & 12,2 & 12,2 & 12,0 \\
\hline Амурская область & 15,6 & 15,7 & 15,2 \\
\hline
\end{tabular}


Окончание табл. 3

\begin{tabular}{|l|c|c|c|}
\hline \multicolumn{1}{|c|}{1} & 2 & 3 & 4 \\
\hline Магаданская область & 9,5 & 9,3 & 8,7 \\
\hline Сахалинская область & 8,5 & 8,2 & 7,8 \\
\hline Еврейская автономная область & 23,7 & 23,9 & 23,7 \\
\hline Чукотский автономный округ & 8,8 & 8,5 & 8,0 \\
\hline
\end{tabular}

Сост. по: [Уровень жизни].

В 2020 г., по сравнению с 2019 г., сохранилась либо несущественно снизилась доля населения с денежными доходами ниже величины прожиточного минимума в Камчатском крае и Республике Бурятия; в остальных регионах отмечено заметное снижение. Это обусловлено несущественным ростом величины прожиточного минимума в 2020 г. и заметным приростом среднедушевых денежных доходов населения.

\section{Заключение и обсуждение результатов исследования}

Анализируемый трехлетний период сопровождался для российской экономики рядом негативных тенденций: введение и расширение санкционной политики стран Запада, высокая волатильность на финансовых рынках, неустойчивость цен на мировых рынках углеводородных ресурсов, карантинные ограничения из-за продолжения пандемии и др., однако величина располагаемых ресурсов и доля домохозяйств с доходами выше прожиточного минимума в ряде регионов увеличились или сохранились на прежнем уровне, что способствовало более высокому уровню сбережений. При этом темп прироста сбережений выше темпа прироста наличных средств на руках у населения. Возросла доля организованных сбережений домохозяйств. Объяснение вышяперечисленному, по мнению автора, кроется в следующем.

Во-первых, неустойчивая финансово-экономическая ситуация и введение «пандемийных ограничений» способствовали не только сужению сфер трат доходов домохозяйств (приобретение товаров, покупка транспортных средств, туризм и др.), но и некоторому трансформированию стандартов потребления. Так, в структуре расходов домохозяйств существенно возросла доля расходов на домашнее питание при снижении расходов на кафе и рестораны, организацию отдыха и культурные мероприятия. В течение 2020 г. произошло вынужденное сокращение объемов текущего потребления домохозяйств из-за введенных ограничений, однако неизрасходованная часть доходов в большей степени обусловлена отложенным спросом, а не инвестиционными предпочтениями.

Проведенный опрос (участники: 86 домохозяйств или 302 жителя Республики Бурятия, из которых 79 человек младше 25 лет, 167 человек - в возрасте от 25 до 55 лет, 56 человек - старше 55 лет) показал, что в условиях «пандемийных ограничений» основной причиной сбережений стало: возможное ухудшение финансово-экономической ситуации в будущем (43,7 \% респондентов); отсутствие «физической доступности» для совершения покупок из-за объявленного в стране локдауна (29,5 \% респондентов); добровольный отказ от текущих покупок, в основном, товаров длительного пользования (2,9 \% респондентов); стремление приумножить средства за счет их вложения в доходные финансовые активы (2,6 \% респондентов); иное (21,3 \% респондентов). Представленные результаты опроса коррелируют с мнением руководителя направления «Макроэкономический анализ и финансовые рынки» ЦСР Натальи Сафиной, согласно которому определяющая причина роста сбережений в течение 2020 г. кроется не в повышении благосостояния, а в неуверенности в завтрашнем дне, что и предопределяет сберегательное поведение, заставляет формировать запас прочности «на черный день» [Доходы россиян снизились...].

Во-вторых, происходит формирование устойчивых групп домохозяйств, ориентированных на определенные места «размещения» накоплений. Так, домохозяйства с низкими и невысокими доходами главным образом предпочитают хранить средства 
в виде наличных, домохозяйства с высокими доходами - в виде банковских вкладов либо в высокодоходных финансовых активах. Таким образом, сбережения в современных условиях все меньше зависят от динамики доходов, а определены, в большей степени, сберегательным поведением, т. е. являются социальным выбором членов домохозяйства.

Результаты проведенного опроса свидетельствуют о том, что аккумулируемые накопления домохозяйства предпочитают хранить: только дома в виде наличных средств (31,4 \% респондентов); в банке (небольшая часть дохода в виде депозитов и вкладов) и дома (большая часть доходов в виде наличных денег) $(12,0 \%$ респондентов); в банке (большая часть дохода в виде депозитов и вкладов) и дома (небольшая часть доходов в виде наличных денег) (9,6 \% респондентов); только в банке в виде депозитов и вкладов (19,9\% респондентов); в драгоценных металлах и на обезличенных металлических счетах (6,6 \% респондентов); в иностранной валюте и на валютных счетах $(17,6$ \% респондентов); иное, включая инвестиционные вложения, размещенные на ПАММсчетах (2,9\% респондентов).

В-третьих, несмотря на то, что в динамике трехлетнего периода наблюдается снижение доли населения с денежными доходами ниже величины прожиточного минимума и уменьшается значение коэффициента Джини, субъективная оценка изменений в уровне жизни и восприятие будущего как индикаторы, отражающие социальное «самочувствие», ухудшаются. Так, индекс потребительских настроений домохозяйств снизился до рекордно низких значений [Потребительские настроения...]. В конечном итоге это может привести к деструктивным изменениям в потребительском и сберегательном поведении.

Субъективное восприятие изменений в уровне жизни показывает, что большая часть опрошенных указывает на заметное ухудшение финансового положения членов домохозяйства (48,0 \% респондентов), примерно равные доли опрошенных отмечают несущественное ухудшение (20,5\%) или отсутствие ухудшения $(19,9 \%)$, и небольшая часть опрошенных показывают улучшение (11,6 \% респондентов).

Наибольшее опасение в обозримой перспективе у большинства участников опроса связано с возможной потерей работы из-за финансово-экономических проблем в организации, сокращения штатов или численности $(40,1 \%$ респондентов), задержкой выплаты или уменьшением размера заработной платы $(20,5 \%)$, ростом цен на основные товары и услуги (19,1%), инфляционным обесцениванием денежных сбережений (3,9\% респондентов).

В условиях финансово-экономической нестабильности аккумулирование денежных сбережений домохозяйств осуществляется, в большей степени, для обеспечения «подушки» финансовой безопасности и создания такого резерва, который может быть использован при ухудшении финансового положения (формирование отложенного спроса); в меньшей - как инвестиционный ресурс с целью приумножения капитала и получения дополнительного дохода в будущем. Перечисленное выше обуславливает необходимость разработки комплекса мер по стимулированию склонности домохозяйств к сбережению и мотивации к трансформированию аккумулируемых средств в инвестиционные активы.

\section{Источники и литература}

Доходы россиян снизились, но сбережения выросли вдвое // Ведомости [Электронный pecypc]. - Режим доступа: https://www.vedomosti.ru/economics/articles/2021/02/09/857333dohodi-rossiyan (дата обращения: 27.04.2021).

Доходы, расходы и потребление домашних хозяйств в 2020 году (по итогам выборочного обследования бюджетов домашних хозяйств) [Электронный ресурс]. - Режим доступа: https://gks.ru/bgd/regl/b20_102/Main.htm (дата обращения: 17.03.2021).

Елисеев Д. О. Сберегательный потенциал населения России: проблемы и перспективы развития / Д. О. Елисеев, Ю. В. Наумова, А. В. Лебедева // Региональные проблемы преобразования экономики. - 2013. - № 4. - С. 30-39. 
Каврук E. C. Факторы, влияющие на сберегательное поведение населения и снижение сбережений населения в условиях кризиса [Электронный ресурс] / Е. С. Каврук // Научный журнал КубГАУ. - № 56(02). - 2010. - Режим доступа: http://ej.kubagro.ru/2010/02/pdf/08.pdf (дата обращения: 27.02.2021).

Маратканова И. В. Влияние факторов внутренней и внешней среды на сберегательное поведение домашних хозяйств России / И. В. Маратканова // Финансы и кредит. - 2019. № 1(781). - С. 159-176.

Потребительские настроения населения РФ снизились до 4-летнего минимума - ЦБ РФ [Электронный ресурс]. - Режим доступа: http://www.finmarket.ru/news/5362371 (дата обращения: 05.04.2021).

Семенюта О. Г. Сберегательный потенциал и потенциал сбережений населения: анализ дефиниций / О. Г. Семенюта, Т. В. Гончаренко // Научные ведомости Белгородского государственного университета. Вып. 18/1. - 2011. - № 7(102). - С. 72-76.

Уровень жизни [Электронный ресурс]. - Режим доступа: https://rosstat.gov.ru/ folder/13397 (дата обращения: 22.03.2021).

Численность населения с денежными доходами ниже величины прожиточного минимума, в процентах от общей численности населения [Электронный ресурс]. - Режим доступа: https://fedstat.ru/indicator/33460 (дата обращения: 16.04.2021).

\section{References}

Dohody rossiyan snizilis', no sberezheniya vyrosli vdvoe // Vedomosti [Elektronnyj resurs]. - Rezhim dostupa: https://www.vedomosti.ru/economics/articles/2021/02/09/857333-dohodirossiyan (data obrashcheniya: 27.04.2021).

Dohody, raskhody i potreblenie domashnih hozyajstv v 2020 godu (po itogam vyborochnogo obsledovaniya byudzhetov domashnih hozyajstv) [Elektronnyj resurs]. - Rezhim dostupa: https:// gks.ru/bgd/regl/b20_102/Main.htm (data obrashcheniya: 17.03.2021).

Eliseev D. O. Ś beregatel'nyj potentsial naseleniya Rossii: problemy i perspektivy razvitiya / D. O. Eliseev, Yu. V. Naumova, A. V. Lebedeva // Regional'nye problemy preobrazovaniya ekonomiki. - 2013. - № 4. - S. 30-39.

Kavruk E. S. Faktory, vliyayushchie na sberegatel'noe povedenie naseleniya i snizhenie sberezhenij naseleniya v usloviyah krizisa [Elektronnyj resurs] / E. S. Kavruk // Nauchnyj zhurnal KubGAU. - № 56(02). - 2010. - Rezhim dostupa: http://ej.kubagro.ru/2010/02/pdf/08.pdf (data obrashcheniya: 27.02.2021).

Maratkanova I. $V$. Vliyanie faktorov vnutrennej i vneshnej sredy na sberegatel'noe povedenie domashnih hozyajstv Rossii / I. V. Maratkanova // Finansy i kredit. - 2019. - № 1(781). S. 159-176.

Potrebitel'skie nastroeniya naseleniya RF snizilis' do 4-letnego minimuma - TSB RF [Elektronnyj resurs]. - Rezhim dostupa: http://www.finmarket.ru/news/5362371 (data obrashcheniya: 05.04.2021).

Semenyuta O. G. Sberegatel'nyj potentsial i potentsial sberezhenij naseleniya: analiz definitsij / O. G. Semenyuta, T. V. Goncharenko // Nauchnye vedomosti Belgorodskogo gosudarstvennogo universiteta. Vyp. 18/1. - 2011. - № 7(102). - S. 72-76.

Uroven' zhizni [Elektronnyj resurs]. - Rezhim dostupa: https://rosstat.gov.ru/folder/13397 (data obrashcheniya: 22.03.2021).

Chislennost' naseleniya s denezhnymi dohodami nizhe velichiny prozhitochnogo minimuma, v protsentah ot obshchej chislennosti naseleniya [Elektronnyj resurs]. - Rezhim dostupa: https:// fedstat.ru/indicator/33460 (data obrashcheniya: 16.04.2021). 